\title{
Study protocol: health survey of Sao Paulo: ISA-Physical Activity and Environment
}

\author{
Alex Antonio Florindo ${ }^{1,2,3^{*}}$ (D), Inaian Pignatti Teixeira ${ }^{1,3}$, Ligia Vizeu Barrozo ${ }^{4}$, Flávia Mori Sarti ${ }^{1,2}$, \\ Regina Mara Fisberg ${ }^{2,5}$, Douglas Roque Andrade ${ }^{1,3}$ and Leandro Martin Totaro Garcia,
}

\begin{abstract}
Background: Many studies have investigated the association between the built environment and physical activity behavior in urban settings. However, most of the studies conducted in low- and middle-income countries were cross-sectional, which are limited to identify behavioral determinants. We propose a prospective cohort study to verify the relationship between built environment features and leisure-time and transport-related physical activity in adults from Sao Paulo city, Brazil.

Methods: Prospective multilevel cohort, denominated "ISA-Physical Activity and Environment". It will build on the Health Survey of Sao Paulo in 2015 ("Inquérito de Saúde de São Paulo (ISA)" in Portuguese). The Health Survey of Sao Paulo, originally designed as a cross-sectional survey, had a multi-stage sample, covering 150 census tracts distributed in five health administrative areas. Data collection was performed by face-to-face interviews until December 2015 and the sample comprised 4043 individuals aged 12 years or more. The ISA-Physical Activity and Environment study will reassess people who are aged 18 years or more in 2020, including telephone and household interviews. The primary outcome will be leisure-time and transport-related physical activity, assessed through the International Physical Activity Questionnaire long version. Exposure variables will be built environment features in the areas participants live and work in the follow-up. Data analysis will include multivariate multilevel linear and logistic models. We will also conduct cost-effectiveness analysis and develop agent-based models to help inform decision-makers. The study will be conducted by an interdisciplinary research team specialized in physical activity epidemiology, nutritional epidemiology, georeferencing applied to health, statistics, agent-based modeling, public health policy, and health economics.

Discussion: There are few longitudinal studies on the relationship between the built environment and physical activity behavior in low- and middle-income countries. We believe that the ISA-Physical Activity and Environment study will contribute with important results for the progress of the knowledge in this field and for the implementation of policies that promote leisure-time physical activity and active travel in Sao Paulo and similar cities across the world.
\end{abstract}

Keywords: Built environment, Leisure-time physical activity, Active travel, Cohort, Adults

* Correspondence: aflorind@usp.br

'School of Arts, Sciences and Humanities, University of Sao Paulo, Rua Arlindo Bettio, 1000, Sao Paulo, SP 03828-000, Brazil

${ }^{2}$ Graduate Program in Nutrition in Public Health, School of Public Health, University of Sao Paulo, Sao Paulo, Brazil

Full list of author information is available at the end of the article

\section{Background}

Leisure-time physical activity and active transportation are behaviors significantly associated with the prevention of chronic non-communicable diseases and the promotion of healthier environments. Cities that encourage physical activity among their inhabitants usually present important results in the reduction of greenhouse gas

(c) The Author(s). 2021 Open Access This article is licensed under a Creative Commons Attribution 4.0 International License, which permits use, sharing, adaptation, distribution and reproduction in any medium or format, as long as you give appropriate credit to the original author(s) and the source, provide a link to the Creative Commons licence, and indicate if changes were made. The images or other third party material in this article are included in the article's Creative Commons licence, unless indicated otherwise in a credit line to the material. If material is not included in the article's Creative Commons licence and your intended use is not permitted by statutory regulation or exceeds the permitted use, you will need to obtain permission directly from the copyright holder. To view a copy of this licence, visit http://creativecommons.org/licenses/by/4.0/ The Creative Commons Public Domain Dedication waiver (http://creativecommons.org/publicdomain/zero/1.0/) applies to the data made available in this article, unless otherwise stated in a credit line to the data. 
emissions and motorized traffic, improvement in social capital, and an increase of green areas [1-7]. However, studies addressing physical activity behavior among adults in Latin American countries presented varied results throughout the last decades.

A survey involving more than 370 thousand adults in Brazilian states' capitals from 2006 to 2012 showed that there was a $2 \%$ annual increase in the proportion of people doing at least $150 \mathrm{~min}$ of leisure-time physical activity. However, this study showed a larger decrease in active transportation: 13\% per year between 2006 and 2008 and 6\% between 2009 and 2012 [8]. Another recent study conducted in Sao Paulo city, Brazil, including more than 21 thousand adults, showed a 7.9 p.p. increase in exercise or sports in leisure time from 2006 to 2016 [9]. However, in Colombia, a study involving more than 27 thousand adults between 2005 and 2010 indicated a reduction in leisure-time physical activity, although there was an increase in walking for transportation [9].

The impact of physical activity on health is wellestablished, as well as the fact that physical activity is affected by complex multidimensional factors that can hinder or facilitate behavioral changes for more active lifestyles worldwide. A study published in the Lancet series on physical activity showed more than 70 characteristics associated with physical activity behavior in populations from low- and middle-income countries [10], a large number of these features are associated with cities' built and natural environment. Cities' environmental characteristics refer to physical features such as patterns of land use, street connectivity, and number and diversity of destinations reachable by walking or cycling from households, including parks, squares, clubs, gyms, bicycling paths, schools, and public transportation [11].

However, most of the studies on the role of cities' built environment on leisure-time and transport-related physical activity have been conducted in high-income countries, which present socioeconomic and cultural aspects that are different from low- and medium-income countries [12]. Besides, most studies published in low- and middle-income countries are based on cross-sectional data, limiting their capacity to answer whether different built environment features can affect physical activity behavior [12]. A systematic review published in 2012 indicated that $89 \%$ of the studies identified a significant association between features from the built environment and physical activity level in diverse populations [13].

Epidemiologic studies conducted in Brazil from 2010 onwards showed that people living within buffers of 500 $\mathrm{m}$ to $1500 \mathrm{~m}$ with a higher density of bicycling pathways, parks, gyms, subway or train stations, improved walkability, and mixed destinations, had a higher probability of engaging in leisure-time and transport-related physical activity $[2,14-18]$. These studies were important to identify potential associations between exposure to certain built environment features and physical activity behavior; however, they present limitations and uncertainty regarding trends and causality [19]. For instance, it is uncertain whether individuals were already physically active and therefore chose to live in environments with improved infrastructure, or whether neighborhoods with better built environment features contributed to enhancing physical activity levels.

Few longitudinal studies have been proposed to assess potential causal links between the built environment and physical activity level in high-income countries [20-22], and even less in low- and middle-income countries. The lack of longitudinal data in large multicultural middleincome countries like Brazil is an important knowledge gap that needs to be addressed, particularly considering recent changes in Brazilian society. It is the case of Sao Paulo, the largest city in Brazil, with more than 12 million inhabitants and one of the ten largest cities worldwide, which had an urban masterplan approved in 2014 targeting environmental inequities to improve the quality of life of its residents.

Therefore, additional efforts in the analysis of individual, environmental and social determinants and correlates of physical activity are required in developing countries, especially considering the potential postCOVID-19 developments, which may have long-term impacts on physical activity levels.

\section{Aims of the study}

The "Health Survey of Sao Paulo: Physical Activity and Environment" ("Inquérito de Saúde de São Paulo-ISA: Atividade Física e Ambiente" in Brazilian Portuguese) is a prospective cohort study in Sao Paulo city, Brazil, focusing on the evolution and the association between built environment features of the areas where people live and work and leisure-time physical activity and active travel. Other secondary objectives include the analysis of the relationship between the built environment and sedentary behavior, nutritional status, mobility, the incidence of diseases, and mental health.

\section{Methods}

Study design

A prospective multilevel cohort of individuals living in the city of Sao Paulo, Brazil.

\section{Settings and study population Setting}

The study will be conducted in Sao Paulo city, Brazil, which has a population of 12,325,232 million inhabitants as of 2020, being the most densely populated region in the country (8102.79 inhabitants per $\mathrm{km}^{2}$ ) and one of 
the ten most populated cities worldwide. It is organized into 96 districts, grouped in 32 sub-prefectures, six health administrative areas, and, as of 2019, included 27, 149 census tracts.

\section{Baseline}

The longitudinal study builds on the Health Survey of Sao Paulo conducted in 2015 as its baseline. The Health Survey of Sao Paulo 2015 was a cross-sectional health survey coordinated by researchers from the University of Sao Paulo, Campinas State University, and Health Institute of Sao Paulo, in partnership with the Sao Paulo $\mathrm{Mu}$ nicipal Secretary of Health. The survey aimed at providing data on prevalence and potential correlates of the population's health and lifestyle, generating evidence for public policies in the city.

The sample design and methodological procedures of the Health Survey of Sao Paulo 2015 were published elsewhere [23]. Briefly, the sample design had two levels: (1) census tracts; and (2) households. In the first stage, 150 census tracts across five health administrative areas (30 census tracts per area) were selected. In the second stage, visits were conducted in 5469 households: 18.3\% in the North region, $21.8 \%$ in the Middle-West region, $21.8 \%$ in the Southeast region, $20.5 \%$ in the South region, and $17.6 \%$ in the Southeast region. Face-to-face interviews were conducted in households with 4043 individuals aged 12 years or more from August 2014 to December 2015.

\section{ISA-Physical Activity and Environment study}

For the longitudinal study, participants of the Health Survey of Sao Paulo 2015 who are aged 18 years or more at the time of the new interview will be invited to participate in the follow-up. Data collection will be done in household visits and telephone interviews (Fig. 1).

Considering the restrictions imposed after the COVID-19 pandemics, the initial follow-up interview during 2020 will be performed through telephone, adopting the standard methodology used in the Surveillance of Risk and Protection Factors for Chronic Diseases by Telephone Survey (VIGITEL), from the Brazilian Ministry of Health [24]. The method is based on computer-assisted telephone interviewing (CATI), which is conducted by an interviewer using a computer to complete the survey directly in an electronic questionnaire during the telephone call. At the end of the interview, the answers are readily available within the survey dataset for analysis. Other data collection stages will be performed in 2022 .

\section{Sampling power for longitudinal analysis}

Cohort and natural experiment studies have been able to reassess at least $70 \%$ of the baseline sample in intervals of 2 to 3 years $[20,25,26]$. Considering that the main exposure variables in the study refer to the built environment near interviewees' households, as parameters to calculate sample size we adopted the results of a crosssectional study performed using the same sample, which focused on the association between access to public open spaces (e.g., parks, squares, and bicycle paths within distances up until $500 \mathrm{~m}$ of participants' households) with leisure walking [17]. The prevalence in the exposed group (individuals who had access to two or more built environment features within $500 \mathrm{~m}$ from their household) was $26.9 \%$ and prevalence in the nonexposed group was $18.9 \%$. Adopting a significance level of 5 and $90 \%$ power for single-tailed hypothesis testing

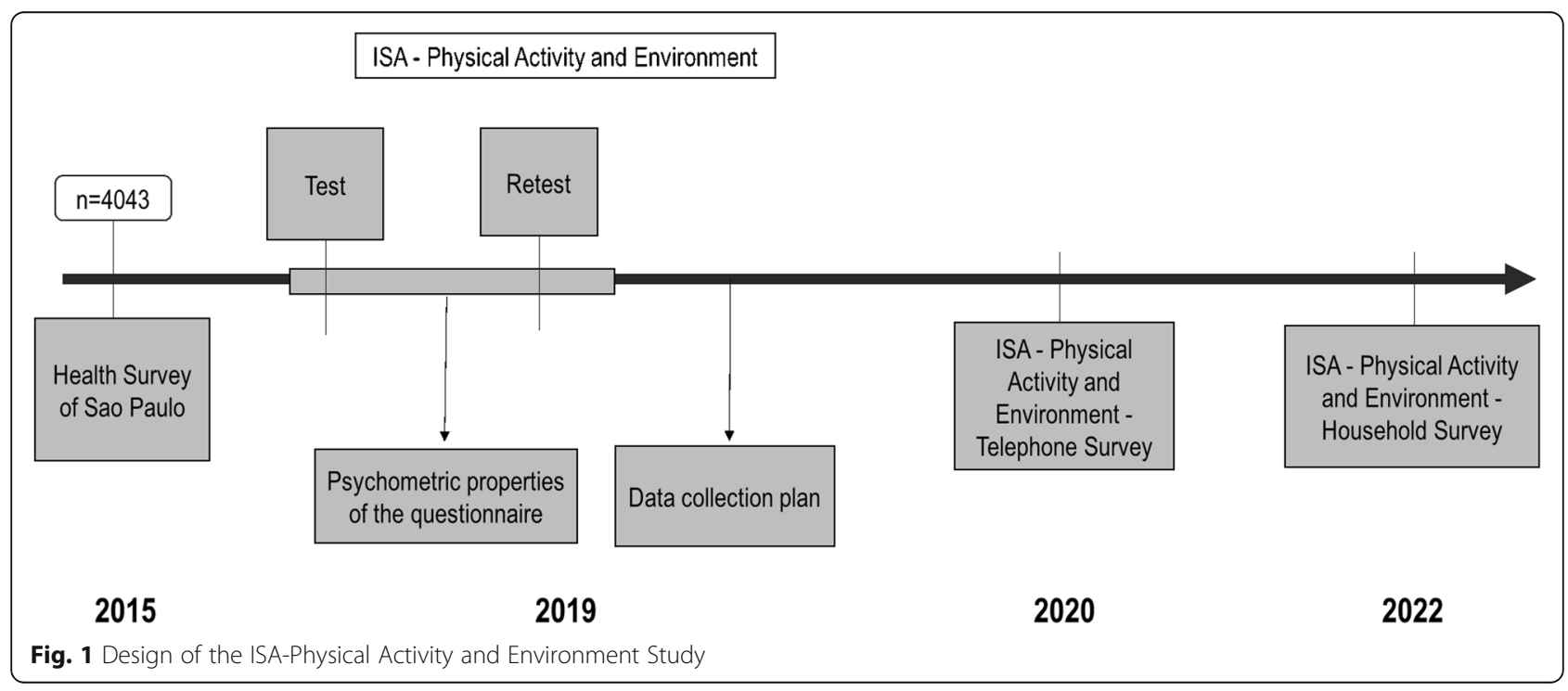


in a cohort study, at least 469 people per exposure group should be sampled.

\section{Research team}

The study encompasses an interdisciplinary research team specialized in physical activity epidemiology, nutritional epidemiology, georeferencing applied to health, statistics, agent-based modeling, public health policy and health economics, from the University of Sao Paulo (Brazil), other research institutions from the state of Sao Paulo and other Brazilian states, Australia, United Kingdom, Portugal, and United States.

\section{Ethical aspects}

The ISA-Physical Activity and Environment study was approved by the Ethics Committee of the School of Arts, Sciences and Humanities at the University of Sao Paulo on April 08, 2019 (protocol number 10396919.0.0000.5390).

\section{Individual-level data collection}

The questionnaires adopted for telephone and household interviews are based on the Health Survey of Sao Paulo. Physical activity level will be assessed using the International Physical Activity Questionnaire (IPAQ) long version [27], standardized to evaluate activities performed in a typical week. The method has been used in previous studies on the associations between the built environment and physical activity in South American countries, and questions about leisure-time and transport-related physical activity are adequate to assess physical activity in these domains in countries like Brazil and Colombia [27].

The reproducibility of the IPAQ was tested in a sample of 43 individuals (mean age $=45.7$ years; standarddeviation $(\mathrm{sd})=20.3$; range $=18$ to 82 ). The average interval between interviews was 8.2 days $(\mathrm{sd}=1.3$; range $=7$ to 11 ). Results indicated that there were no statistically significant differences between the first and the second interviews in each of the domains of physical activity, as well as for leisure walking and moderate-tovigorous activity, and for transport-related cycling and walking. After dichotomization, results from the first and second interviews of each domain and type of physical activity were significantly associated, with an agreement higher than $70 \%$ in all domains and types.

The questionnaires include 11 thematic sections in the 2020 telephone interview and 20 thematic sections in the face-to-face interviews from 2022 onwards. The description of variables that will comprise the primary and secondary outcomes in the study are provided in Table 1.

\section{Accelerometer-based assessment of physical activity}

Those sampled to participate in the study in 2022 will receive accelerometers (Actigraph, model GT3X) to be used in the wrist for $24 \mathrm{~h}$ per day, for seven consecutive

Table 1 Dimensions of the questionnaires adopted in the ISA-Physical Activity and Environment study in Sao Paulo city, Brazil

\begin{tabular}{lll}
\hline Dimension & Evaluations & Wave 3 - Face-to-face interviews $^{n}$ \\
\cline { 2 - 3 } & Wave 2 - Telephone interviews & Yes $^{\text {a }}$ \\
\hline Physical activity & Yes & Yes $^{\text {a }}$ \\
Sedentary behavior & Yes & Yes \\
Perceived environment & Yes & Yes \\
Self-efficacy for physical activity & No & Yes \\
Social support for physical activity & No & Yes \\
Barriers to physical activity & No & Yes \\
Mobility and transportation & Yes & Yes \\
Sleep & Yes & Yes \\
Nutritional status & Yes & Yes \\
Food consumption & No & Yes \\
Perceived health status & Yes & Yes \\
Emotional health & No & Yes \\
Self-report of diseases & Yes & Yes \\
Socioeconomic level & Yes & Yes \\
Household characteristics & Yes & No \\
Physical activity during the COVID-19 pandemic & Yes & No \\
Obesity during the COVID-19 pandemic & Yes & Yes \\
Self-assessment of neighborhood & Yes &
\end{tabular}

${ }^{a}$ Self-report and accelerometer 
days, to register physical activity, sedentary, and sleep behaviors [28-32].

\section{Built environment data collection}

A geoprocessing process will be implemented to obtain built environment data using primarily geographic information systems, obtained through an online library of geospatial data publicly available at the Sao Paulo Municipal Government (http://geosampa.prefeitura.sp.gov.br/ PaginasPublicas/_SBC.aspx). Other datasets of interest will also be used during the development of the project, considering information from 2014 onwards.

Data referring to infrastructure, such as green spaces (squares, parks, trees), sports facilities (schools with sports infrastructure, sports centers, community clubs, private clubs, private spaces with sports activities, private gyms, open air gyms), facilities for leisure and transportation (bike paths), education facilities (public schools, private schools, social services units, technical schools, and universities), facilities for leisure and culture (theaters, museums, cinemas, libraries, cultural centers, arts galleries), traffic security (traffic lights, volume of vehicles), public security (street lighting, theft rates, homicide rates), public transport (bus stops, train and subway stations, bus terminal), primary health care units, commerce facilities (supermarkets, restaurants, bakeries, coffee shops, open street markets, fast-food restaurants), and other socioeconomic and physical structures (streets connectivity - including stairways and alleys - topography, commerce density, and residential density).

Built environment data will be considered within 500 $\mathrm{m}, 1000 \mathrm{~m}$ and $1500 \mathrm{~m}$ radius and network around the participants' residence and workplace [33, 34]. The standardization adopted in the baseline studies (Health Survey of Sao Paulo 2015) will also be included in the analysis to improve the quality of the information in the reference period [16-18]. The geoprocessing process will be performed using the ArcGIS Desktop software, version 10.8.1.14362, Copyright (C)1999-2020 Esri Inc.

Beyond geospatial data obtained through geographic information systems, audit analysis will be performed using the Microscale Audit of Pedestrian Streetscapes (MAPS), global version [35]. MAPS is a tool that assesses crossings, street segments, and a route up until $0.72 \mathrm{~km}$ from the interviewees' households, auditing aspects regarding land use, presence of malls and shopping centers, street utilization, aesthetics, social aspects, characteristics of streets and sidewalks, intersection controls, street lights, gutters, crosswalks, signaling for bicycles, dead-end streets, squares, and parks. The tool was originally designed for in loco audits; however, studies from different countries have shown that remote audit is equally reliable [36]. Thus, the present study will apply
MAPS on data imagery provided through Google Street View, which presents panoramic views of the streets.

\section{Interviews with stakeholders}

Complementary to the longitudinal study, organizations from the public, private, and non-governmental sectors have been conducted have been engaged since the beginning of the study. in-depth interviews were conducted to know their perspective on the main challenges to promote and increase physical activity in the city, analyze which problems may be addressed in the study, and maximize the potential for using the evidence that will be obtained for implementing public policies and programs that promote leisure-time and transport-related physical activity, according to the premises proposed by Giles-Corti et al. [37] and Leyden et al. [38]. The organizations were selected considering their representativeness in the areas of physical activity and sports, active transportation, urban mobility, public health, education, and urban development in Sao Paulo city, particularly considering the primary outcomes of the research.

\section{Cost-effectiveness and agent-based modeling}

The study will be followed by an analysis of health impacts and cost-effectiveness of alternative scenarios considering feasible structural changes in the built environment that may influence leisure-time and transport-related physical activity. Data from the survey will be complemented by existing evidence in the literature to propose an agent-based model to simulate daily activities in different neighborhoods and test potential changes in the built environment aimed at the population leisure and transport-related physical activity behavior and to estimate the consequent health impacts of these environmental and behavioral changes. Costeffectiveness analysis applied to scenarios in the agentbased models that show larger impacts on physical activity levels will be performed for primary outcomes and certain secondary outcomes, as described in Table 2 . The results of these two modeling components can then be used to inform potential public policies in infrastructure, health, and leisure in the city.

\section{Measures}

\section{Primary outcomes}

The main outcomes of this study will be 1 . Leisure-time walking; 2. Leisure-time moderate-to-vigorous physical activity; 3. Total leisure-time physical activity (walking, moderate and vigorous activities); 4. Transport-related walking; 5 . Transport-related bicycling.

\section{Main secondary outcomes}

Secondary outcomes include work-related physical activity; household physical activity; sedentary 
Table 2 Aspects included in the economic assessment component of the ISA-Physical Activity and Environment in Sao Paulo city, Brazil

\begin{tabular}{|c|c|c|}
\hline \multirow{2}{*}{$\frac{\text { Components }}{\text { Leisure-time physical activity }}$} & \multicolumn{2}{|l|}{ Outcomes } \\
\hline & Changes in walking duration (minutes) & 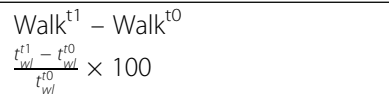 \\
\hline & Changes in moderate-to-vigorous physical activity duration (minutes) & $\begin{array}{l}\text { Mod-Vig }{ }^{\mathrm{t} 1}-\text { Mod-Vig }{ }^{\mathrm{t}} \\
\frac{t_{m v}^{t 1}-t_{m v}^{0}}{t_{m v}^{0}} \times 100\end{array}$ \\
\hline \multirow[t]{2}{*}{ Active travel } & Changes in walking duration (minutes) & $\begin{array}{l}\text { Walk }^{t 1}-\text { Walk }^{\text {to }} \\
\frac{t_{w t}^{t 1}-t_{w t}^{t 0}}{t_{w t}^{0}} \times 100\end{array}$ \\
\hline & Changes in bicycling duration (minutes) & 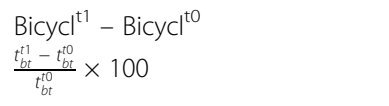 \\
\hline Nutritional status & Change in Body Mass Index (BMl, in kg/m²) & $\begin{array}{l}B M I^{t 1}-B M I^{t 0} \\
\frac{B M I^{11}-B M I^{00}}{B M I^{10}} \times 100\end{array}$ \\
\hline \multirow[t]{9}{*}{ Individual behavior } & \multicolumn{2}{|c|}{ Clothing and other accessories for leisure-time walking (clothes, shoes, and specific accessories for walking) } \\
\hline & \multicolumn{2}{|c|}{$\begin{array}{l}\text { Clothing for leisure-time moderate-to-vigorous physical activity (clothes, shoes, and specific accessories for specific } \\
\text { activities) }\end{array}$} \\
\hline & \multicolumn{2}{|c|}{ Equipment for leisure-time moderate-to-vigorous physical activity (equipment for gymnastics and weight training) } \\
\hline & \multicolumn{2}{|l|}{ Equipment for active travel (bicycle and safety equipment) } \\
\hline & \multicolumn{2}{|l|}{ Equipment maintenance } \\
\hline & \multicolumn{2}{|l|}{ Physical education professionals' wages } \\
\hline & \multicolumn{2}{|l|}{ The opportunity cost of time spent in leisure walking } \\
\hline & \multicolumn{2}{|c|}{ The opportunity cost of time spent in leisure-time moderate-to-vigorous physical activity } \\
\hline & \multicolumn{2}{|l|}{ The opportunity cost of time spent in active travel } \\
\hline \multirow[t]{8}{*}{ Built environment } & \multicolumn{2}{|c|}{ Building and maintenance of leisure facilities (clubs and community centers, parks and squares) } \\
\hline & \multicolumn{2}{|c|}{ Facilities and green spaces for physical activity in public places (trees and equipment for physical activity) } \\
\hline & \multicolumn{2}{|l|}{ Physical education professionals' wages in public sector programs } \\
\hline & \multicolumn{2}{|c|}{ Building and maintenance of active travel facilities (bicycle paths and sidewalks) } \\
\hline & \multicolumn{2}{|l|}{ Public transport infrastructure (train and subway stations and bus stops) } \\
\hline & \multicolumn{2}{|l|}{ Destination mix (density of commercial, leisure, and food facilities) } \\
\hline & \multicolumn{2}{|c|}{$\begin{array}{l}\text { Changes in land use (differences in values of real state, based on municipal taxes: household and commerce density, } \\
\text { commerce/household ratio, street connectivity) }\end{array}$} \\
\hline & \multicolumn{2}{|c|}{$\begin{array}{l}\text { Changes in transportation infrastructure (differences in transportation costs, whether individual or collective, } \\
\text { concerning the adoption of bicycle or walking) }\end{array}$} \\
\hline
\end{tabular}

Obs.: $\mathrm{t}_{\mathrm{wl}}{ }^{\mathrm{to}}=$ duration of leisure walking at baseline; $\mathrm{t}_{\mathrm{wl}}{ }^{\mathrm{t} 1}=$ duration of leisure walking at follow-up; $\mathrm{t}_{\mathrm{mv}}{ }^{\mathrm{to}}=$ duration of moderate-to-vigorous physical activity at baseline; $\mathrm{t}_{\mathrm{mv}}{ }^{\mathrm{t} 1}=$ duration of moderate-to-vigorous physical activity at follow-up; $\mathrm{t}_{\mathrm{wt}}{ }^{\mathrm{to}}=$ duration of transport-related walking at baseline; $\mathrm{t}_{\mathrm{wt}}{ }^{\mathrm{t}}=\mathrm{duration}$ of transport-related walking at follow-up; $\mathrm{t}_{\mathrm{bt}}{ }^{\text {to }}=$ duration of transport-related bicycling at baseline; $\mathrm{t}_{\mathrm{bt}}{ }^{\mathrm{t}}=$ duration of transport-related bicycling at follow-up; $\mathrm{BMI}^{\mathrm{to}}=$ Body Mass Index at baseline; $\mathrm{BMI}^{\mathrm{t}}$ = Body Mass Index at follow-up

behavior; body mass index; nutritional status; quality of food consumption; mental diseases; respiratory diseases; hypertension; type 2 diabetes; sleep patterns; urban mobility patterns; perceived environment for physical activity; self-efficacy for physical activity; social support for physical activity; exercise and nutritional status during COVID-19 pandemics; socioeconomic level.

\section{Data analysis}

The estimation of primary outcomes (physical activity levels) and exposures (built environment features) will be based on differences between the baseline survey (conducted until 2015) and follow-up measures.

Multivariate multilevel linear and logistic models will be estimated to consider census tracts, households, and confounding variables. Directed acyclic diagrams will be adopted for the identification and selection of confounding variables for the regression models.

Moderation and mediation analysis will be performed to investigate whether and how the built environment influences physical activity behavior through changes in psychological attributes and the moderating role of certain socio-economic conditions. In addition, data in 
2020 will be used to investigate the effects of restrictions due to COVID-19 pandemics on physical activity levels, and changes in body weight.

The cost-effectiveness analysis will be based on the observed effects of changes in the built environment on health outcomes. The method usually adopted in economic evaluations of public health policies and programs $[39,40]$ is based on the comparison of costs and health outcomes between groups of individuals allocated in intervention and control groups; therefore, in the present study, those who will have and have not experienced changes in the built environment will serve as intervention and control groups, respectively. Comparisons between individuals living in regions with different levels of the built environment for physical activity will also be conducted.

Analyses will be performed using the software MAXQDA Standard Educational, IBM SPSS Statistics version 24.0, Stata version 16.1, and NetLogo.

\section{Discussion}

An international research project in partnership with Australian researchers was initiated in 2016 and 2017 to develop built environment indicators to inform physical activity promotion initiatives in Sao Paulo city [17], addressing the lack of studies in large metropolitan areas in Latin American countries. This initial study used cross-sectional data from the Health Survey of Sao Paulo 2015, which will comprise the baseline for this new prospective cohort study. Results indicated that adults who had access to two or more public open spaces (e.g., bike pathways, squares, and parks) in a radius of $500 \mathrm{~m}$ around their households presented a higher probability of leisure-time walking in comparison to individuals without access to those spaces around their households [17]. Moreover, people living up to $500 \mathrm{~m}$ from bike pathways had a higher probability of using the bicycle for transport in comparison to individuals without access to those structures nearby [16], and adults living in $500 \mathrm{~m}$ buffers with more mixed destinations adopted walking for transport more frequently than others [18].

However, longitudinal studies are required to avoid potential self-selection bias [19] and to obtain robust evidence on the effects of the built environment on health outcomes, especially in low- and middle-income countries undergoing rapid societal transition processes [12]. Well-established examples of longitudinal studies conducted in high-income countries are the "RESIDential Environment Study (RESIDE)" [20] and the "How Areas in Brisbane Influence Health and Activity (HABITAT)" [41], both in Australia, and the I-Connect [21], in the United Kingdom. More recently, the "Examining Neighbourhood Activity in Built Living Environments (ENABLE London study)", which followed 1278 adults during 2 years, showed that an increase in walkability index, a decrease of distances between participants' houses to parks, and an increase of public transportation access were associated with higher levels of walking [42].

Our study builds on the Health Survey of Sao Paulo 2015 with the main objective of obtaining and analyzing robust data to expand the scientific evidence that can inform public policy decision making towards healthy environments for physical activity promotion in low- and middle-income countries. We collect information on diverse built environment features from the areas where people live and work and their association with physical activity-related outcomes, especially leisure and transport ones, and estimate the potential population-level impacts of changes in the built environment, contributing to the planning and implementation of strategic changes in the urban design of Sao Paulo. Additionally, it will be possible to estimate the potential effects of COVID-19 restrictions on physical activity levels.

Another important planned outcome of our study will be the objective assessment of environmental characteristics in multiple time points, allowing the observation of changes in the built environment over the year and how they can affect health outcomes. Complementarily, built environment audits combining the MAPS method [35] and Google Street View will allow the observation of environmental features at scale, helping us to create and improve indicators that may be used to plan strategic actions to improve the population's wellbeing. Processes for data extraction and estimation of built environment indicators using well-designed geoprocessing methods, like the ones applied by the "International Physical Activity and the Environment Network (IPEN)" [43], are essential to test hypotheses on the relationships between the built environment and leisure-time and transportrelated physical activity and to provide reliable evidence to inform the development and implementation of physical activity promotion initiatives.

The IPAQ long version is widely adopted for the assessment of physical activity in studies that investigate the relationship between built environment and physical activity behavior (e.g., IPEN study [44]), and has been extensively used in studies in Latin American countries [27]. The IPAQ long version enables the investigation of each physical activity domain independently, a critical advantage for our study given that physical activity behavior in different domains may be affected by different environmental properties. The questionnaire was standardized to register physical activity in a typical week and it will allow the identification of changes throughout the follow-up period, particularly after COVID-19 pandemics. Additional questions regarding objectives, places, types, and duration of practices adopted by the participants were included for the face-to-face 
interviews, as well as questions on sedentary behavior in leisure and at work. The additional questions included did not affect the validity and reproducibility of the questionnaire, according to the reproducibility assessment performed with a sample of 43 individuals.

A potential disadvantage of IPAQ refers to its subjectivity and reliance on individuals' memory, in addition to the overestimation of physical activity [45]. To counter these drawbacks our study will adopt an objective assessment of physical activity by accelerometry to collect movement patterns for $24 \mathrm{~h}$ per day over 1 week, including details on sleep, sedentary behavior, and light, moderate and vigorous physical activity [28-32].

Regarding nutritional status, self-reported weight and height were previously validated in a subsample of 856 participants of the 2015 survey [46]. Calibration coefficients for correction of weight, height, and BMI were also proposed in the study, considering sex, age, leisure-time physical activity, and exposure to cardiometabolic risk factors. The results obtained indicated that self-reported measurements of weight, height, and BMI were valid for telephone and face-to-face interviews, presenting intraclass correlation coefficients higher than 0.60 and, after calibration, an increase in the accuracy of self-reported measurements. Therefore, it will be possible to estimate with improved precision the prevalence of obesity in the follow-up study.

The results of the agent-based models and costeffectiveness analysis of potential changes in the built environment can inform future policies aimed at promoting physical activity at scale, allowing those responsible for decision-making processes in infrastructure, health, and leisure programs to identify opportunities to provide, improve, and sustain environments that are conducive to wellbeing through physical activity, health and quality of life.

Another challenge that our study wants to address is the utilization of evidence by stakeholders involved in physical activity promotion. Thus, the engagement with actors and representatives of organizations and groups of the population has been extremely important in the study design and planning for implementation actions [37].

Finally, considering the lack of longitudinal studies in low- and middle-income countries, we believe that the ISA-Physical Activity and Environment will contribute with important results for the advancement of the knowledge on relationships between variables referring to the built environment nearby households and work, and leisure-time physical activity and active transportation.

\section{Abbreviations \\ IPAQ: International Physical Activity Questionnaire; ISA: Health Survey of Sao Paulo}

\section{Acknowledgments}

We are thankful for the support of the investigators of the Health Survey of Sao Paulo Study (Marilisa Berti de Azevedo Barros, Ph.D., University of
Campinas, Campinas city, Sao Paulo State, Brazil; Maria Cecília Goi Porto Alves, Ph.D., Health of Institute, Sao Paulo city, Sao Paulo State, Brazil; Moises Goldbaum, Ph.D., and Chester Luiz Galvão Cesar, Ph.D., University of Sao Paulo, Sao Paulo city, Sao Paulo State, Brazil) and of the Physical Activity Epidemiology Group at the University of Sao Paulo, Brazil.

\section{Authors' contributions}

AAF had the idea of this study and lead the writing. IPT and LVB contributed to the georeferencing of built environment variables. RMF contributed to nutritional status variables. FMS contributed to cost-effectiveness analysis. FMS and LMTG contributed to agent based-model. DRA contributed to stakeholder interviews. AAF, IPT, FMS, and LMTG contributed to statistical analysis. AAF, GT, JPASB, MSC, LVG, and MG contributed to results interpretation. All authors contributed to drafting and critically revising the manuscript and approved the final version.

\section{Funding}

We received external funding from the Sao Paulo Research Foundation (FAPESP), Brazil (funding number 2017/17049-3). The content is solely the responsibility of the authors and does not necessarily represent the official views from FAPESP. Funders do not have any role in the execution of the study nor the interpretation or report of the results.

Availability of data and materials

Not applicable because this paper describes the protocol of the study.

\section{Ethics approval and consent to participate}

The Ethics Committee of the School of Arts, Sciences, and Humanities at the University of Sao Paulo approved the study (process number 10396919.0.0000.5390). In the telephone interview of the longitudinal study, the consent of participants will be verbal, and in the household interview, and for wearing accelerometers the consent of participants will be written.

\section{Consent for publication}

Not applicable.

\section{Competing interests}

The authors declare that they have no competing interests.

\section{Author details}

${ }^{1}$ School of Arts, Sciences and Humanities, University of Sao Paulo, Rua Arlindo Bettio, 1000, Sao Paulo, SP 03828-000, Brazil. ' Graduate Program in Nutrition in Public Health, School of Public Health, University of Sao Paulo, Sao Paulo, Brazil. ${ }^{3}$ Physical Activity Epidemiology Group, University of Sao Paulo, Sao Paulo, Brazil. ${ }^{4}$ Department of Geography, School of Philosophy, Literature and Human Sciences, University of Sao Paulo, Sao Paulo, Brazil. ${ }^{5}$ Department of Nutrition, School of Public Health, University of Sao Paulo, Sao Paulo, Brazil. ${ }^{6}$ Centre for Public Health, Queen's University Belfast, Belfast, UK.

Received: 21 December 2020 Accepted: 18 January 2021

Published online: 04 February 2021

\section{References}

1. Sugiyama T, Cerin E, Owen N, Oyeyemi AL, Conway TL, Van Dyck D, Schipperijn J, Macfarlane DJ, Salvo D, Reis RS, et al. Perceived neighbourhood environmental attributes associated with adults recreational walking: IPEN adult study in 12 countries. Health Place. 2014;28C:22-30.

2. Siqueira Reis R, Hino AA, Ricardo Rech C, Kerr J, Curi Hallal P. Walkability and physical activity: findings from Curitiba, Brazil. Am J Prev Med. 2013;45(3): 269-75

3. Moore SC, Patel AV, Matthews CE, Berrington de Gonzalez A, Park Y, Katki HA, Linet MS, Weiderpass E, Visvanathan K, Helzlsouer K, et al. Leisure time physical activity of moderate to vigorous intensity and mortality: a large pooled cohort analysis. PLoS Med. 2012;9(11):e1001335.

4. Giles-Corti B, Foster S, Shilton T, Falconer R. The co-benefits for health of investing in active transportation. N S W Public Health Bull. 2010; 21(5-6):122-7.

5. Frank LD, Sallis JF, Conway TL, Chapman JE, Saelens BE, Bachman W. Many pathways from land use to health: associations between neighborhood 
walkability and active transportation, body mass index, and air quality. JAPA. 2006;72(1):75-87.

6. Muller-Riemenschneider F, Pereira G, Villanueva K, Christian H, Knuiman M, Giles-Corti B, Bull FC. Neighborhood walkability and cardiometabolic risk factors in Australian adults: an observational study. BMC Public Health. 2013; 13:755.

7. Wood L, Shannon T, Bulsara M, Pikora T, McCormack G, Giles-Corti B. The anatomy of the safe and social suburb: an exploratory study of the built environment, social capital and residents' perceptions of safety. Health Place. 2008:14(1):15-31.

8. Mielke GI, Hallal PC, Malta DC, Lee IM. Time trends of physical activity and television viewing time in Brazil: 2006-2012. Int J Behav Nutr Phys Act. 2014; 11:101.

9. González S, Sarmiento L, Lozano O, Ramírez A, Grijalba C. Niveles de actividad física de la población colombiana: desigualdades por sexo y condición socioeconómica. Biomédica. 2014;34(3):447-59.

10. Bauman AE, Reis RS, Sallis JF, Wells JC, Loos RJ, Martin BW, Lancet Physical Activity Series Working G. Correlates of physical activity: why are some people physically active and others not? Lancet. 2012;380(9838):258-71.

11. Brownson RC, Hoehner CM, Day K, Forsyth A, Sallis JF. Measuring the built environment for physical activity: state of the science. Am J Prev Med. 2009; 36(4 Suppl):S99-123 e112.

12. Elshahat S, O'Rorke M, Adlakah D. Built environment correlates of physical activity in low- and middle-income countries: A systematic review. PLoS One. 2020;15(3):e0230454.

13. Ferdinand AO, Sen B, Rahurkar S, Engler S, Menachemi N. The relationship between built environments and physical activity: a systematic review. Am J Public Health. 2012;102(10):e7-e13.

14. Hino AA, Reis RS, Sarmiento OL, Parra DC, Brownson RC. Built environment and physical activity for transportation in adults from Curitiba, Brazil. J Urban Health. 2013;91(3):446-62.

15. Hino AA, Reis RS, Sarmiento OL, Parra DC, Brownson RC. The built environment and recreational physical activity among adults in Curitiba, Brazil. Prev Med. 2011;52(6):419-22.

16. Florindo AA, Barrozo LV, Turrell G, Barbosa J, Cabral-Miranda W, Cesar CLG, Goldbaum M. Cycling for transportation in Sao Paulo city: associations with bike paths, train and subway stations. Int J Environ Res Public Health. 2018; 15(4):562.

17. Florindo AA, Barrozo LV, Miranda WC, Rodrigues EQ, Turrell G, Goldbaum M, Cesar CLG, Giles-Corti B. Public open spaces and leisure time walking in Brazilian adults. Int J Environ Res Public Health. 2017;14(6):553.

18. Florindo AA, Barbosa JBAS, Barrozo LV, Andrade DR, Aguiar BS, Failla MA, Gunn L, Mavoa S, Turrell G, Goldbaum M. Walking for transportation and built environment in Sao Paulo city, Brazil. J Transp Health. 2019:15:100611.

19. McCormack GR, Shiell A. In search of causality: a systematic review of the relationship between the built environment and physical activity among adults. Int J Behav Nutr Phys Act. 2011;8:125.

20. Giles-Corti B, Bull F, Knuiman M, McCormack G, Van Niel K, Timperio A Christian $H$, Foster S, Divitini M, Middleton $N$, et al. The influence of urban design on neighbourhood walking following residential relocation: longitudinal results from the RESIDE study. Soc Sci Med. 2013;77:20-30.

21. Goodman A, Sahlqvist S, Ogilvie D, iConnect c. Who uses new walking and cycling infrastructure and how? Longitudinal results from the UK iConnect study. Prev Med. 2013;57(5):518-24.

22. Humphreys DK, Panter J, Sahlqvist S, Goodman A, Ogilvie D. Changing the environment to improve population health: a framework for considering exposure in natural experimental studies. J Epidemiol Community Health. 2016:70(9):941-6.

23. Alves M, Escuder MML, Goldbaum M, Barros MBA, Fisberg RM, Cesar CLG. Sampling plan in health surveys, city of Sao Paulo, Brazil, 2015. Rev Saude Publica. 2018:52:81

24. Moura EC, Neto OLM, Malta DC, Mouta L, Silva NN, Bernal R, Claro RM, Monteiro CA. Vigilância de Fatores de Risco para Doenças Crônicas por Inquérito Telefônico nas capitais dos 26 estados brasileiros e no Distrito Federal (2006). Rev Bras Epidemiol. 2008;11(S1):20-37.

25. Goodman A, Sahlqvist S, Ogilvie D, iConnect C. New walking and cycling routes and increased physical activity: one- and 2-year findings from the UK iConnect study. Am J Public Health. 2014;104(9):e38-46.

26. Pazin J, Garcia LM, Florindo AA, Peres MA, Guimaraes AC, Borgatto AF, Duarte Mde F. Effects of a new walking and cycling route on leisure-time physical activity of Brazilian adults: a longitudinal quasi-experiment. Health Place. 2016;39:18-25,

27. Hallal PC, Gomez LF, Parra DC, Lobelo F, Mosquera J, Florindo AA, Reis RS, Pratt M, Sarmiento OL. Lessons learned after 10 years of IPAQ use in Brazil and Colombia. J Phys Act Health. 2010;7(Suppl 2): S259-64.

28. Rowlands AV, Yates T, Davies M, Khunti K, Edwardson CL. Raw accelerometer data analysis with GGIR R-package: does accelerometer brand matter? Med Sci Sports Exerc. 2016;48(10):1935-41.

29. Rowlands AV, Fraysse F, Catt M, Stiles VH, Stanley RM, Eston RG, Olds TS. Comparability of measured acceleration from accelerometry-based activity monitors. Med Sci Sports Exerc. 2015;47(1):201-10.

30. Doherty A, Jackson D, Hammerla N, Plotz T, Olivier P, Granat MH, White T, van Hees VT, Trenell MI, Owen CG, et al. Large scale population assessment of physical activity using wrist worn accelerometers: the UK biobank study. PLoS One. 2017;12(2):e0169649

31. van Hees VT, Thaler-Kall K, Wolf KH, Brond JC, Bonomi A, Schulze M, Vigl M, Morseth B, Hopstock LA, Gorzelniak L, et al. Challenges and opportunities for harmonizing research methodology: raw accelerometry. Methods Inf Med. 2016;55(6):525-32.

32. Troiano RP, McClain JJ, Brychta RJ, Chen KY. Evolution of accelerometer methods for physical activity research. Br J Sports Med. 2014;48(13):1019-23.

33. Sallis JF, Cerin E, Conway TL, Adams MA, Frank LD, Pratt M, Salvo D, Schipperijn J, Smith G, Cain KL, et al. Physical activity in relation to urban environments in 14 cities worldwide: a cross-sectional study. Lancet. 2016; 387(10034):2207-17.

34. McCormack GR, Giles-Corti B, Bulsara M. The relationship between destination proximity, destination mix and physical activity behaviors. Prev Med. 2008:46(1):33-40

35. Cain KL, Geremia CM, Conway TL, Frank LD, Chapman JE, Fox E, Timperio A, Veitch J, Van Dyck D, Verhoeven $H$, et al. Development and reliability of a streetscape observation instrument for international use: MAPS-global. Int J Behav Nutr Phys Act. 2018;15(1):19.

36. Phillips CB, Engelberg JK, Geremia CM, Zhu W, Kurka JM, Cain KL, Sallis JF, Conway TL, Adams MA. Online versus in-person comparison of microscale audit of pedestrian streetscapes (MAPS) assessments: reliability of alternate methods. Int J Health Geogr. 2017;16(1):27.

37. Giles-Corti B, Sallis JF, Sugiyama T, Frank LD, Lowe M, Owen N. Translating active living research into policy and practice: one important pathway to chronic disease prevention. J Public Health Policy. 2015;36(2):231-43.

38. Leyden KM, Slevin A, Grey T, Hynes M, Frisbaek F, Silke R. Public and stakeholder engagement and the built environment: a review. Curr Environ Health Rep. 2017:4(3):267-77.

39. Sarti FM, Cyrillo DC. Avaliação de custos em projetos de economia da saúde. p. 316-329. In: Nita ME, Secoli SR, Nobre MRC, Ono-Nita SK, Campino ACC, Sarti FM, Costa AMN, Carrilho FJ, editors. Avaliação de tecnologias em saúde: Evidência clínica, análise econômica e análise de decisão. Edited by ARTMED. Porto Alegre; 2010. p. 600. <in portuguese>.

40. Sarti FM, Campino ACC. Fundamentos de economia da saúde e farmacoeconomia. p.225-236. In: Nita ME, Secoli SR, Nobre MRC, Ono-Nita SK, Campino ACC, Sarti FM, Costa AMN, Carrilho FJ, editors. Avaliação de tecnologias em saúde: Evidência clínica, análise econômica e análise de decisão. Edited by ARTMED. Porto Alegre; 2010. p. 600. <in portuguese>.

41. Burton NW, Haynes M, Wilson LA, Giles-Corti B, Oldenburg BF, Brown WJ, Giskes K, Turrell G. HABITAT: a longitudinal multilevel study of physical activity change in mid-aged adults. BMC Public Health. 2009;9:76.

42. Clary C, Lewis D, Limb E, Nightingale CM, Ram B, Page AS, Cooper AR, Ellaway A, Giles-Corti B, Whincup PH, et al. Longitudinal impact of changes in the residential built environment on physical activity: findings from the ENABLE London cohort study. Int J Behav Nutr Phys Act. 2020;17(1):96.

43. Adams MA, Frank LD, Schipperijn J, Smith G, Chapman J, Christiansen LB, Coffee N, Salvo D, du Toit L, Dygryn J, et al. International variation in neighborhood walkability, transit, and recreation environments using geographic information systems: the IPEN adult study. Int J Health Geogr. 2014;13:43.

44. Kerr J, Sallis JF, Owen N, De Bourdeaudhuij I, Cerin E, Sugiyama T, Reis R, Sarmiento O, Fromel K, Mitas J, et al. Advancing science and policy through a coordinated international study of physical activity and built environments: IPEN adult methods. J Phys Act Health. 2013;10(4):581-601. 
45. Hallal PC, Victora CG, Wells JC, Lima RC, Valle NJ. Comparison of short and full-length international physical activity questionnaires. J Phys Act Health. 2004;1(3):227-34.

46. Fisberg RM, Sales CH, Fontanelli MM, Pereira IL, Alves MCGP, Escuder MML, et al. Health survey of São Paulo with focus in nutrition: rationale, design, and procedures. Nutrients. 2018;10(2):169.

\section{Publisher's Note}

Springer Nature remains neutral with regard to jurisdictional claims in published maps and institutional affiliations.

Ready to submit your research? Choose BMC and benefit from:

- fast, convenient online submission

- thorough peer review by experienced researchers in your field

- rapid publication on acceptance

- support for research data, including large and complex data types

- gold Open Access which fosters wider collaboration and increased citations

- maximum visibility for your research: over $100 \mathrm{M}$ website views per year

At $\mathrm{BMC}$, research is always in progress.

Learn more biomedcentral.com/submissions 